УДК 316.7

$10.17213 / 2075-2067-2021-3-90-94$

\title{
КАТЕГОРИЯ УСПЕХА В ЦЕННОСТНОЙ КАРТИНЕ МИРА РОССИЯН: ДИНАМИЧЕСКИЙ АСПЕКТ
}

\author{
(C) 2021 г. O. В. Фетисова
}

\section{Южный федеральный университет, г. Ростов-на-Дону, Россия}

Цель исследования. В статье рассматривается динамика развития категории успеха в иенностной картине мира россиян. Успех связывается с идентификацией и самоидентификацией личности, прежде всего, с карьерной идентичностью. Успех обусловлен включенностью человека в социальную структуру, а механизмом этого включения выступает собственно трудовая деятельность.

В результате исследования доказано, что Истинный успех в иенностной картине мира россиян определяется как результат сбалансированности личного и общественного в ориентаџиях личности и конкретной социальной группы, а преобладание одного начала над другим не может свидетельствовать о жизненном успехе.

Ключевые слова: идентификация; динамический аспект; иееностная картина мира; успех; сочииальная группа.

\section{THE CATEGORY OF SUCCESS IN THE VALUE PICTURE OF THE WORLD OF RUSSIANS: A DYNAMIC ASPECT}

\section{(C) 2021 O. V. Fetisova}

\section{Southern Federal University, Rostov-on-Don, Russia}

The purpose of the study. The article examines the dynamics of the development of the category of success in the value picture of the world of Russians. Success is associated with the identification and self-identification of the individual, primarily with career identity. Success is due to the inclusion of a person in the social structure, and the mechanism of this inclusion is the actual work activity.

As a result of the research, it is proved that the true success in the value picture of the world of Russians is defined as the result of the balance of the personal and social orientations of the individual and a particular social group, and the predominance of one principle over the other can not indicate life success.

Key words: identification; dynamic aspect; value picture of the world; success4 social group.

Последние десятилетия ознаменованы актуализацией проблемы идентификации, обнаружения собственной идентичности, которая становится важной практически для каждого человека. Безусловно, наиболее эффективными следует считать исследования, которые проводятся на междисциплинарных основаниях, когда в сферу социологии включается 
методология и концептуальные подхода целого ряда наук гуманитарной парадигмы - философии, психологии, культурологии.

Процесс идентификации и самоидентификации личности осуществляется при опоре на константы, которые не подвергаются трансформации под воздействием внешних факторов, при этом продуктивным этот процесс будет вне зависимости от степени осознанности дифференциации миров $Я$ и не- $Я$ конкретной личностью или социальной группой. Закономерно также и то, что личность в данном процессе может применять для самоидентификации осознанные усилия либо опираться на собственный опыт, а также нормы и традиции социума. В настоящее время ясно одно: проблематика идентификации коррелирует с возрастанием динамики развития современного общества, в том числе в связи с возникновением кризисных обстоятельств.

Проблематика идентификации становится в современном социуме столь острой не только вследствие неустойчивости и неупорядоченности жизни, напротив, по всей видимости, упорядочение индивидуальной и коллективной жизни инициирует у личности тенденцию к обособлению с целью самоидентификации и в то же время в поисках коллективной идентичности. Поэтому вполне можно констатировать амбивалентный характер индивидуальных усилий в усвоении компонентов ценностной картины мира социальной группы или общества в целом, что подтверждает аксиому о взаимосвязи личности и общества.

Современная Россия оказывается в этом случае весьма репрезентабельным полем для изучения различных социальных процессов, в том числе связанных с утверждением новых ценностей или реабилитацией, трансформацией или модификацией уже существующих. Отечественный исторический процесс, демонстрирующий неоднократный кризис существующей в конкретный период ценностной картины мира, позволяет прослеживать динамику тех или иных ее компонентов в различные хронологические промежутки. Так, динамика трансформаций категории успеха показательна в плане сопоставления их развития в координатах советского и постсоветского исторических периодов. Категория успеха закономерно кор- релирует с понятием идентификации, в том числе карьерной идентичности.

Карьера представляет собой одновременно процесс и результат утверждения социальной идентичности. Социология оперирует понятием карьерной идентичности на основании изучения внутрипоколенной социальной мобильности $[1,2]$. Подчеркнем в этой связи, что карьера как одно из условий жизненного успеха вбирает в себя как оценку человеком уже приобретенного статуса, так и определенный потенциал в плане карьерного роста. Трудовая карьера значима и в плане поиска и воспроизводства социальной идентичности в целом: так, для западных обществ карьерный успех и продвижение в служебной иерархии обнаруживает тесную связь с ценностями и образцами успеха, свойственными конкретному культурному коллективу.

В современной России именно карьера занимает ведущее положение в иерархии средств достижения успеха, что детерминирует отношение к ней как к одной из ценностей современной мировой культуры, а успех начинает отождествляться именно с карьерой.

Р. Тернер отмечает, что отличия классовых обществ фокусируются не только в сфере понимания успеха, но и в признании конкретных образцов успеха, а также в выборе приемлемых средств для его достижения [3]. Приоритетный образец карьеры несколько десятилетий назад являл собой тот, кто был занят собственным бизнесом на основании стимулирования предпринимательства. Однако в XXI в. ориентиры становятся иными: «Поскольку развитие нашей экономики дает недостаточно простора для развития малого бизнеса, можно вырасти и в рамках гигантских бюрократических организаций частного предпринимательства. Если нет больше возможности быть королем своего собственного детища, то можно, в крайнем случае, стать президентом одной из экономических организаций с демократическим устройством. Сегодняшнее положение человека, является ли он посыльным или клерком, не имеет значения: следует лишь остановить свой пристальный взгляд на вершине» [4, c. 122]. Поэтому западные образцы карьеры ориентированы в настоящее время, скорее, на иерархическое устройство экономических организаций. 
Советский и отчасти постсоветский период в развитии отечественной культуры обнаруживает определенную индифферентность в отношении карьерной идентичности, прежде всего, в координатах ценностной картины мира среди тех ценностей и образцов поведения, которые являются наиболее приемлемыми и предписываются гражданину. Социологическая традиция, как известно, предписывает различать ценности-нормы и ценности-объект [5], и трудовая карьера не квалифицируется длительное время как ценность-норма. Советская идеологическая парадигма диктует либо нейтральное отношение к карьере, либо, реже, негативную оценку. Нельзя, разумеется, говорить о полном отрицании необходимости карьеры как таковой в советском обществе, однако она не является той ценностью, которой члены общества стараются обладать. Иными словами, карьера не входит в состав понятия идентификации. На наш взгляд, противоречие здесь заключается в четкой иерархизированности и структурированности советского общества, в котором массово осуществлялись различные перемещения внутри формальных и неформальных позиций.

Условием успеха всегда является включенность человека в социальную структуру, а механизм этого включения - собственно трудовая деятельность. Процесс труда формирует механизм продуцирования его результатов, которые настоятельно необходимы и для индивида, и для общества. И материальные, и духовные потребности связаны с пониманием необходимости результатов, которые в этих случаях обусловлены разными факторами, но всегда дают импульс для конкретной деятельности. Тем не менее, общество потребления порождает «отчуждение» труда, когда индивид включен часто вне его согласия в такие социальные структуры, которые ориентированы на удовлетворение только материальных потребностей. Это сообщает человеку односторонность и во многом приводит к разочарованиям. Если труд человека не признан обществом, то для него это становится психологической и социальной катастрофой. Для постсоветского периода развития России свойственно непризнание труда целого ряда социальных групп, что породило не только социальную напряженность, но и вызвало духовный кризис общества.

Аксиоматично для социологии и других гуманитарных наук утверждение о том, что именно социальное признание результатов деятельности человека является определяющей составляющей его жизненного успеха. Категория успеха осмысливается не только и не столько в координатах компонентов, которые зачастую навязаны социумом - высокая заработная плата или доходы иного порядка, престижная профессия, обладание властью и пр. Истинный успех в ценностной картине мира россиян определяется как результат сбалансированности личного и общественного в ориентациях личности и конкретной социальной группы, а преобладание одного начала над другим не может свидетельствовать о жизненном успехе.

Безусловно, абсолютизация материальных компонентов существования человека приводит к его изоляции, к социальному обесцениванию его жизни, к потере ее смысла, а также к невозможности трансляции образца успеха, его модели в течение длительного периода времени. Приобретая статус, деньги, власть, человек уверяет себя, что он успешен, однако результаты такой ориентированности на внешний успех не могут быть переданы другим людям и исчезают. Также закономерно и то, что абсолютизация исключительно социального успеха приводит к игнорированию обществом интересов личности, что не может быть приемлемым с позиций индивида. В этом случае социум не даст ничего взамен человеку, получив от него максимум производительных результатов.

Современное российское общество характеризуется перемещением сферы ценности успеха в деловую сферу, что вполне понятно: успех именно в этой области тесно взаимодействует с ценностью уверенности в надежности своего общественного и профессионального статуса. Обобщение разноплановых исследований приводит в социологии к возникновению двух гипотез успеха, которые в целом применимы и к российской действительности начала XXI в.: в качестве исходного постулата первой выступает утверждение о существовании страха успеха в любом обществе, вторая опирается на тезис об отсутствии такого страха и даже мотива 
избегания успеха, тогда как приоритетной для человека становится соревновательная или кооперационная стратегия деятельности. В таком случае мотивировка избегания успеха заключается в стремлении уклониться от конкуренции, соревновательности [6].

Такое сложное многоуровневое отношение к ценности успеха наиболее заметно в сфере межорганизационных и внутриорганизационных отношений. Кооперационная стратегия предполагает, что участники взаимодействия связаны друг с другом позитивно, их успех - совместный, а они как участники взаимодействия должны избегать конфликтов. Соревновательная стратегия предполагает определенную поведенческую динамику, т. к. участники взаимодействия считают свои цели связанными негативно: этот фактор обусловливает несопоставимость индивидуального успеха в социальной группе.

Понятие успеха в деловой сфере закономерно связано с понятием сотрудничества, которое также представляет ценность. Успех также невозможно представить вне понятия лидерства, однако А.Г. Асмолов правомерно считает, что современная модель успеха в ценностной картине мира россиян не включает прежние модели лидерства, которые зачастую опирались на тезис «победителей не судят». Логика реализации категории успеха видится исследователем в другом: за каждым членом общества признается индивидуальная траектория развития и пути достижения успеха, а главным становится поддержание вариативности в претворении моделей успеха в своей жизни. В этом случае задача социума - вовсе не отбор наиболее сильных, которые способны достичь высоких результатов и одержать победу, а, напротив, поддержка всех тех, кто выбирает траекторию успеха, в плане сравнения себя с собой же вчерашним [7].

Категория успеха в ценностной картине мира россиян продолжает претерпевать трансформации, что диктует необходимость в разработке новых концепций успеха применительно к конкретному состоянию современного общества при опоре на классические и неоклассические модели. Необходимо отличать успех - идеологему и успех - ценность: первая представляет собой развитие идеологии общества, вторая является резуль- татом развития аксиологической системы фундамента ценностной картины мира. Также необходимо учитывать различия между тем, что переживается как успех, и тем, что соответствует конкретным социальным критериям успеха.

Закономерно и то, что материальные и духовные ценности социальных групп различны, поэтому и критерии категории успеха вариативны, и эта вариативность усиливается, в том числе и в координатах одного культурного пространства. Оценки, самооценки и представления индивида обусловливаются социокультурным контекстом, динамичным по своему характеру, и эта динамика может быть не только положительной, но и отрицательной, тормозящей индивидуальное стремление к успеху. Социальная среда может стать средоточием культуры «антиуспешности», которая подразумевает подозрительное отношение ко всему выделяющемуся, к прорывам в любой общественно значимой области и одобряет раздражение, а иногда и враждебность ко всему экстраординарному. Поскольку социокультурная среда не однородна, то и ее влияние не может быть однозначным. Социально значимые успехи достижимы для человека только при условии, если он покинет первичные группы своей социализации, где находится под контролем социальной группы.

\section{Литература}

1. Barley S.R. Careers, Identities, and Instututions: The Legasy of the Chicago School of Sociology // Handbook of Career Theory. Cambridge: Cambridge University Press, 1989. - P. 41-65.

2. Brooklyn D.C., Laurent A. The Internal and External Career: A Theoretical and CrossCultulral Perspective // Handbook of Career Theory. - Cambridge: Cambridge University Press, 1989. - P. 454-471.

3. Тернер P. Сравнительный контент-анализ биографий // Вопросы социологии. 1992. - №1. - C. 121-133.

4. Мертон Р. К. Социальная теория и социальная структура // Социальные исследования. - 1992. - №2. - С. 118-124.

5. Костенко Н.В., Оссовский В.Л. Ценности профессиональной деятельности. К.: Наук. думка, 1986. - 151 с. 
6. Хубер Р. Моральные дилеммы успеха // Этика успеха. Вестник исследователей, консультантов, ЛПР. - 1994. — №3. - С. 117-118.

7. Асмолов А.Г. О моделях успеха в эволюции цивилизации // Этика успеха. 1996. — №8. - С. 9-15.

\section{References}

1. Barley S.R. Careers, Identities, and Instututions: The Legasy of the Chicago School of Sociology // Handbook of Career Theory. - Cambridge: Cambridge University Press, 1989. - P. 41-65.

2. Brooklyn D.C., Laurent A. The Internal and External Career: A Theoretical and CrossCultulral Perspective // Handbook of Career Theory. - Cambridge: Cambridge University Press, 1989. - P. 454-471.

3. Terner $R$. Sravnitel'nyj kontent-analiz biografij [Comparative content analysis of biogra- phies] // Voprosy sociologii [Questions of sociology]. - 1992. — №1. - Pp. 121-133.

4. Merton R.K. Social'naja teorija i social'naja struktura [Social theory and social structure] // Social'nye issledovanija [Social research]. — 1992. — №2. — Pp. 118-124.

5. Kostenko N.V., Ossovskij V.L. Cennosti professional'noj dejatel'nosti [The values of professional activity]. - Kiev: Nauk. dumka, 1986. - $151 \mathrm{p}$.

6. Huber R. Moral'nye dilemmy uspeha [Moral dilemmas of success] // Jetika uspeha. Vestnik issledovatelej, konsul'tantov, LPR [The ethics of success. Bulletin of researchers, consultants, LPR]. - 1994. — №3. - Pp. 117-118.

7. Asmolov A.G. O modeljah uspeha v jevoljucii civilizacii [On models of success in the evolution of civilization] // Jetika uspeha [The ethics of success]. - 1996. — №8. - Pp. 9-15.

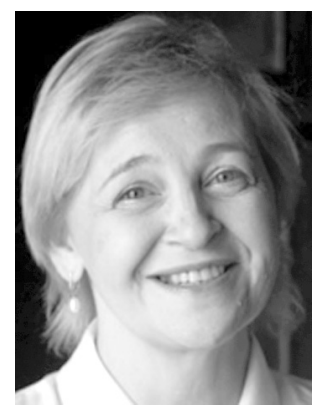

Фетисова Ольга Викторовна - старший преподаватель Высшей школы бизнеса Южного Федерального университета.

Fetisova Olga Viktorovna - Senior Lecturer of the High School of Business, Southern Federal University.

344019 , г. Ростов-на-Дону, ул. 23-я Линия, 43

43 23d Liniya st., 344019, Rostov-on-Don, Russia

E-mail: batum.olga.fetisova@yandex.ru 